\title{
IN SITU GLOBAL METHOD FOR MEASUREMENT OF OXYGEN DEMAND AND MASS TRANSFER
}

K. Thomas Klasson

Chemical Technology Division

Oak Ridge National Laboratory ${ }^{1}$

Oak Ridge, Tennessee 37831

Karin M. O. Lundbäck, Edgar C. Clausen, and James L. Gaddy

Department of Chemical Engineering

University of Arkansas

Fayetteville, Arkansas 72701

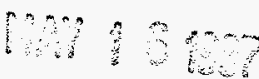

087

Publication

Poster Presentation

$19^{\text {th }}$ Symposium on Biotechnology for Fuels and Chemicals

Colorado Springs, Colorado, May 4-8, 1997

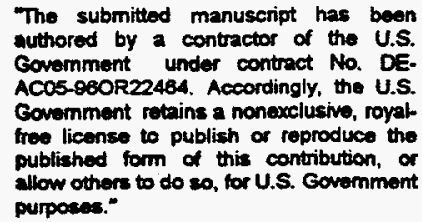

purposes."

\footnotetext{
${ }^{1}$ Managed by Lockheed Martin Energy Research Corp. for the U.S. Department of Energy under contract DE-AC05-96OR22464
} 


\section{DISCLAIMER}

This report was prepared as an account of work sponsored by an agency of the United States Government. Neither the United States Government nor any agency thereof, nor any of their employees, make any warranty, express or implied, or assumes any legal liability or responsibility for the accuracy, completeness, or usefulness of any information, apparatus, product, or process disclosed, or represents that its use would not infringe privately owned rights. Reference herein to any specific commercial product, process, or service by trade name, trademark, manufacturer, or otherwise does not necessarily constitute or imply its endorsement, recommendation, or favoring by the United States Government or any agency thereof. The views and opinions of authors expressed herein do not necessarily state or reflect those of the United States Government or any agency thereof. 


\section{DISCLAIMER}

Portions of this document may be illegible in electronic image products. Images are produced from the best available original document. 
In Situ Global Method for Measurement of Oxygen Demand and Mass Transfer

\author{
K. Thomas Klasson* \\ Chemical Technology Division, Oak Ridge National Laboratory," Oak Ridge, Tennessee 37831-6044 \\ Karin M. O. Lundbäck, Edgar C. Clausen, and James L. Gaddy \\ Department of Chemical Engineering, University of Arkansas, Fayetteville, Arkansas 72701
}

\title{
Summary
}

Two aerobic microorganisms, Saccharomycopsis lipolytica and Brevibacterium lactofermentum, have been used in a study of mass transfer and oxygen uptake from a global perspective using a closed gas system. Oxygen concentrations in the gas and liquid were followed using oxygen electrodes, and the results allowed for easy calculation of in situ oxygen transport. The cell yields on oxygen for $S$. lipolytica and $B$. lactofermentum were 1.01 and $1.53 \mathrm{~g} / \mathrm{g}$ respectively. The mass transfer coefficient was estimated as $10 \mathrm{~h}^{-1}$ at $500 \mathrm{rpm}$ for both fermentations. The advantages with this method are noticeable since the use of model systems may be avoided, and the in situ measurements of oxygen demand assure reliable data for scale-up.

\section{Introduction}

In order to properly design and scale up aerobic fermentations, the oxygen requirements must be known, and appropriate methods must be developed for determining mass transfer coefficients and microbial oxygen uptake for bench-scale systems. Several methods for determining oxygen transfer rates have been reviewed (I). This paper presents an alternative global method that may be applied to most bench-scale systems, either biological or chemical. The major advantage of the method is the in situ measurement rather than the use of model systems such as glucose oxidase or sulfite. Thus, problems associated with differences in medium or physical properties are effectively eliminated with this global technique. Some other methods (e.g., Warburg apparatus) rely on measuring oxygen uptake parameters in systems where the dissolved oxygen concentration may be essentially zero. Such systems are unsuitable for lysine fermentations for which oxygen limitation induces lactate production (2), thus giving a "false" oxygen uptake rate. Other advantages with the presented method are that only oxygen concentration

\footnotetext{
Author to whom all correspondence and reprint requests should be addressed.

"Oak Ridge National Laboratory is managed by Lockheed Martin Energy Research Corp. for the U.S. Department of Energy under contract DE-AC05-960R22464
} 
measurements (partial pressure), not gas flow rates, are needed and that changes in the mass transfer coefficient during a fermentation due to changes in surface tension, etc., may be detected. In this paper, oxygen uptake in two aerobic fermentations is examined: citric acid production using $S$. lipolytica and lysine production using $B$. lactofermentum.

\section{Methods}

Microorganisms. Saccharomycopsis (Candida) lipolytica, NRRL Y-7576, was maintained on YM-broth agar (1.5\%) slants. Brevibacterium lactofermentum, ATCC 21788, was kept on slants consisting of $1 \%$ peptone, $1 \%$ yeast extract, $0.5 \% \mathrm{NaCl}$, and $1.5 \%$ agar.

Medium. The medium used in the fermentation with $S$. lipolytica was a glucose, yeast extract, and salts mixture (3), and a glucose, soytone, and salts medium was used in the experiment with $B$. lactofermentum (4). The fermentation jar was filled with $1 \mathrm{~L}$ of medium and steam sterilized at 1 atm (15 psig) for $30 \mathrm{~min}$. After cooling, each medium was inoculated using $100 \mathrm{~mL}$ of a 24 -h-old seed culture grown in the same medium.

Equipment. The equipment used in the fermentation studies was a BIOSTAT-M (Braun Instruments, Burlingame, CA) fermenter with a working volume of 0.7 to $1.5 \mathrm{~L}$. The fermenter was equipped with $\mathrm{pH}$, agitation, foam, and temperature control, and probes for measuring $\mathrm{pH}$ and dissolved oxygen tension. Cell concentration was estimated from optical density readings and a calibration curve. The measurement of oxygen uptake and in situ mass transfer was performed by connecting a gas bag to the setup. An external oxygen electrode and meter (Yellow Springs Instrument Co., Inc., Yellow Springs, OH) were used to measure the partial pressure of oxygen in the exiting gas from the fermenter. The gas was recirculated to the system using a diaphragm pump inside the gas bag. To prevent $\mathrm{CO}_{2}$ accumulation, the gas was washed continuously with a saturated sodium hydroxide solution. A schematic of the system is displayed in Figure 1. A single three-way valve allowed the gas to bypass the fermenter sparger; two additional valves were used to attach a flask filled with pure $\mathrm{O}_{2}$. Both fermentations were conducted at $30^{\circ} \mathrm{C}$, and the agitation rate was held constant at $500 \mathrm{mpm}$. The gas flow rate was maintained at approximately $2 \mathrm{~L} / \mathrm{min}$.

Oxygen Balance Calculations. In an aerobic fermentation, where nutrients and carbon substrate are plentiful, the rate at which oxygen is supplied to the active enzymes of the cell is often the limiting factor for growth and production $(5,0)$. Since the oxygen required by the cells is supplied from a gas 
phase, there are a number of transport resistances, connected in series, which oxygen transport has to overcome. It is generally recognized that the main resistance to this transport, for sparingly soluble gases such as $\mathrm{O}_{2}$, is in the liquid film (6). Assuming that Henry's law for the equilibrium between gas and liquid interfacial concentrations holds, the following equation is true:

$$
\text { Oxygen transfer rate }=\frac{K_{L} a}{H}\left(p_{G}-p_{L}^{*}\right) V_{L}
$$

At steady state (or pseudo steady state), the oxygen transfer rate equals the oxygen uptake rate by the cells.

In order to estimate the in situ oxygen uptake rate and mass transfer coefficient, additional equipment was attached to the fermenter to achieve a closed gas system. The additional equipment was connected and calibrated after inoculation. The method of oxygen uptake rate was then based on the decrease in the amount of oxygen present in the system.

As mentioned previously, the gas partial pressure of oxygen in the system was determined using an external oxygen electrode calibrated to give readings in partial pressure of oxygen. The total pressure in the system was assumed to be atmospheric since a soft gas bag was used. Any carbon dioxide formed during the fermentation was removed by washing the gas with $\mathrm{NaOH}$, leaving only $\mathrm{O}_{2}, \mathrm{~N}_{2}$, and $\mathrm{H}_{2} \mathrm{O}$. This fact allowed the derivation of an expression for the oxygen present in the system at all times. It was assumed that the gas volume in the system at time zero was equal to $\mathrm{V}$ and that the composition of the gas corresponded to water-saturated air at the temperature $(T)$ and total pressure $(P)$ of the system. After inoculation and electrode calibration, an additional known volume $\left(V_{1}\right)$ of pure oxygen (at $T$ and $P$ ) was connected to the system, and mixing was allowed. The original volume (V) can be calculated from the observed change in the partial pressure of oxygen (from $\mathrm{p}_{\mathrm{O}_{2}}$ to $\mathrm{p}_{\mathrm{O}_{2}}^{\prime}$ ) in the system. Using the ideal gas law, the following expression describing the number of moles of oxygen in the system after mixing of the two volumes may be written:

$$
\frac{\mathrm{p}_{\mathrm{O}_{2}} \mathrm{~V}}{\mathrm{RT}}+\frac{\mathrm{PV}_{1}}{\mathrm{RT}}=\frac{\mathrm{p}_{\mathrm{O}_{2}}^{\prime}\left(\mathrm{V}+\mathrm{V}_{1}\right)}{\mathrm{RT}}
$$

In addition, it is known that the amount of nitrogen present in the system is constant and described by

$$
\mathrm{n}_{\mathrm{N}_{2}}=\frac{\mathrm{p}_{\mathrm{N}_{2}}}{\mathrm{RT}} \mathrm{V}
$$

By solving for $\mathrm{V}$ in Equation (2) and substituting the result into Equation (3), the following expression may be obtained: 


$$
\mathbf{n}_{\mathrm{N}_{2}}=\left(\frac{\mathrm{P}-\mathrm{p}_{\mathrm{O}_{2}}-\mathrm{p}_{\mathrm{H}_{2} \mathrm{O}}}{\mathrm{RT}}\right)\left(\frac{\mathrm{P}-\mathrm{p}_{\mathrm{O}_{2}}^{\prime}}{\mathbf{p}_{\mathrm{O}_{2}}^{\prime}-\mathrm{p}_{\mathrm{O}_{2}}}\right) \mathrm{V}_{1}
$$

The volume of the gas changes during the course of the fermentation as oxygen is consumed by the culture. At any specific time the following equation may be used to calculate this volume:

$$
\text { Gas volume }=\frac{n_{\mathrm{N}_{2}} \mathrm{RT}}{\mathrm{p}_{\mathrm{O}_{2}}}=\frac{\mathrm{n}_{\mathrm{N}_{2}} \mathrm{RT}}{\mathrm{p}_{\mathrm{N}_{2}}}=\frac{\mathrm{n}_{\mathrm{N}_{2}} \mathrm{RT}}{\mathrm{P}-\mathrm{p}_{\mathrm{O}_{2}}-\mathrm{p}_{\mathrm{H}_{2} \mathrm{O}}}
$$

Finally Equation (5) may be rewritten to yield

$$
\mathbf{n}_{\mathrm{O}_{2}}=\frac{\mathrm{p}_{\mathrm{O}_{2}} \mathbf{n}_{\mathrm{N}_{2}}}{\mathbf{P}-\mathrm{p}_{\mathrm{O}_{2}}-\mathrm{p}_{\mathrm{H}_{2} \mathrm{O}}}
$$

in which $\mathrm{p}_{2}$ and $\mathrm{P}$ are measured, $\mathrm{n}_{\mathrm{N}_{2}}$ is a constant obtained from Equation (4), and $\mathrm{p}_{\mathrm{H}_{2} \mathrm{O}}$ can be estimated assuming water saturation of the gas at all times. This derivation does not account for the oxygen present in the liquid. However, when considering the solubility of oxygen in water, it was found that the contribution from the liquid phase to the total amount of oxygen in the system was negligible.

The procedure outlined above was used to determine the oxygen uptake rate for two different microorganisms. The mixing of the two gas volumes (pure oxygen volume and system air volume) took approximately 5 to $10 \mathrm{~min}$. To secure minimal oxygen consumption during this time, the sparger was bypassed (see Figure 1), and the gas was allowed to pass over the liquid, rather than through it. Since measurements of the partial pressure of oxygen in both the gas and liquid $\left(\mathrm{p}_{\mathrm{G}}\right.$ and $\left.\mathrm{p}_{\mathrm{L}}{ }^{*}\right)$ as well as the calculations of oxygen uptake from the gas were made, the overall mass transfer coefficient could be found by rewriting Equation (1) to yield

$$
\frac{d\left(n_{O_{2}}\right)}{d t}=\frac{K_{L} a}{H}\left(p_{G}-p_{L}^{*}\right) V_{L}
$$

\section{Results and Discussion}

The cell concentration and the amount of oxygen remaining in the system are plotted as functions of time in Figures 2 and 3 for the two fermentations using $S$. lipolytica and B. lactofermentum respectively. As is noted in the figures, the amount of oxygen [calculated from Equation (6)] decreased as the cell concentration increased in both fermentations. In the fermentation using $S$. lipolytica (Figure 2), the data 
represent the initial part of the fermentation where cell growth was more pronounced and acids were not formed. The cell yields on oxygen for the two microorganisms are represented in Figure 4, indicating that approximately $\mathbf{5 0 \%}$ more cell mass was obtained in the fermentation with $B$. lactofermentum for the same amount of oxygen consumed. The combined citric and isocitric acid yield on oxygen during the latter part of the fermentation for $S$. lipolytica was $1.33 \mathrm{~g}$ acids $/ \mathrm{g} \mathrm{O}_{2}$ (data not shown).

In Figure 5, the volumetric oxygen transfer rates, calculated as the slope in data presented in Figures 2 and 3, are plotted as a function of the driving force measured by the $\mathrm{O}_{2}$-electrodes. As is noted, all of the data from both fermentations fell on a single straight line, indicating a constant mass transfer coefficient. This was expected since the media and operating conditions were very similar for the fermentations. Using a value of $26.9 \mathrm{~L} \mathrm{~atm} / \mathrm{g} \mathrm{O}_{2}$ for the Henry's law constant (7), the mass transfer coefficient was calculated as $10 \mathrm{~h}^{-1}$ based upon the results obtained in Figure 5. The specific oxygen uptake rates for the two organisms were calculated as $0.32 \mathrm{~g} \mathrm{O}_{2} / \mathrm{h}, \mathrm{g}$ cells for $S$. lipolytica and $0.42 \mathrm{~g} \mathrm{O}_{2} / \mathrm{h}$, $\mathrm{g}$ cells for $B$. lactofermentum during non-oxygen-limiting conditions (in the initial part of the fermentation).

In conclusion, we have demonstrated an alternative method for the measurement of the in situ microbial oxygen uptake and oxygen mass transfer rates. We believe that the advantages with this method are noticeable since the use of model systems may be avoided, and the accurate measurement of microbial oxygen demand assures reliable data for scale-up. The presented method may be easily adapted to any oxygen utilizing system.

\section{Literature Cited}

1. Sobotka, M., Prokop, A., Dunn, I.J. and Eisele, A. (1982), In Annual Reports on Fermentation Processes, vol. 5, Academic Press, New York, pp. 127-210.

2. Ruklisha, M., Marauska, D., Shvinka, J., Toma, M. and Galynina, N. (1981), Biotechnol. Lett. 3, 465470.

3. Klasson, K.T., Clausen, E.C. and Gaddy, J.L. (1989), Appl. Biochem. Biotechnol. 20/21, 491-509.

4. Ackerson, M.D., Clausen, E.C. and Gaddy, J.L. (1989), Appl. Biochem. Biotechnol. 20/21, 511-528.

5. Pirt, S.J. (1975), Principles of Microbe and Cell Cultivation, John Wiley \& Sons, New York, pp. 8193.

6. Bailey, J.E. and Ollis, D.F. (1986), Biochemical Engineering Fundamentals, 2nd ed., McGraw-Hill, New York, pp. 457-532.

7. Faust, A.S., Wenzel, L.A., Clump, C.W., Mous, L. and Andersen, L.B. (1960), In Principles of Unit Operations, John Wiley \& Sons, New York, p. 552. 


\section{Figure Captions}

Figure 1. Experimental setup.

Figure 2. Cell growth and oxygen consumption profiles for the fermentation with S. lipolytica.

Figure 3. Cell growth and oxygen consumption profiles for the fermentation with $B$. lactofermentum.

Figure 4. Cell yield on oxygen for $S$. lipolytica and B. lactofermentum.

Figure 5. Estimation of the overall mass transfer coefficient in both fermentations (agitation $=500 \mathrm{rpm}$ ). 


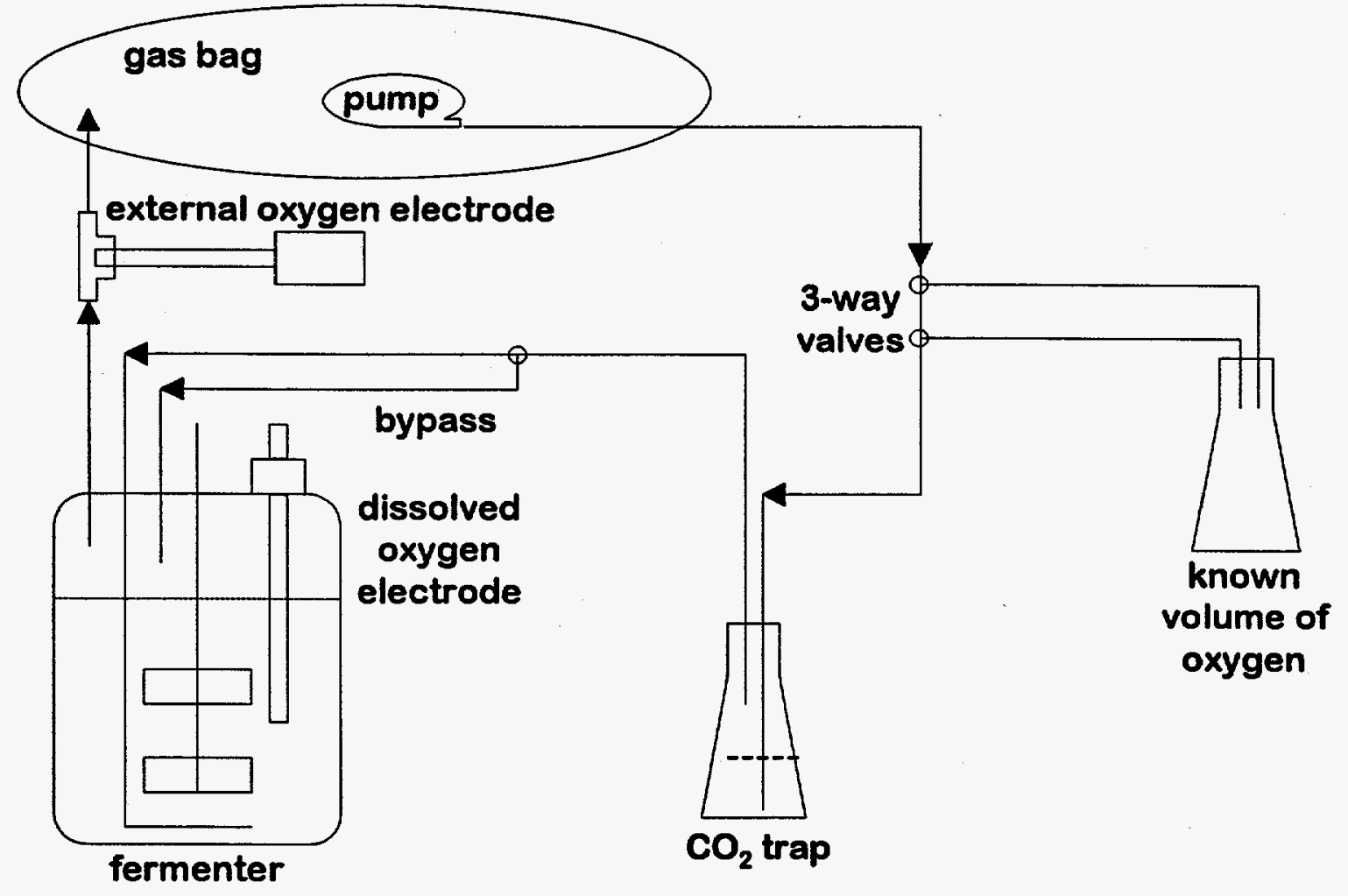




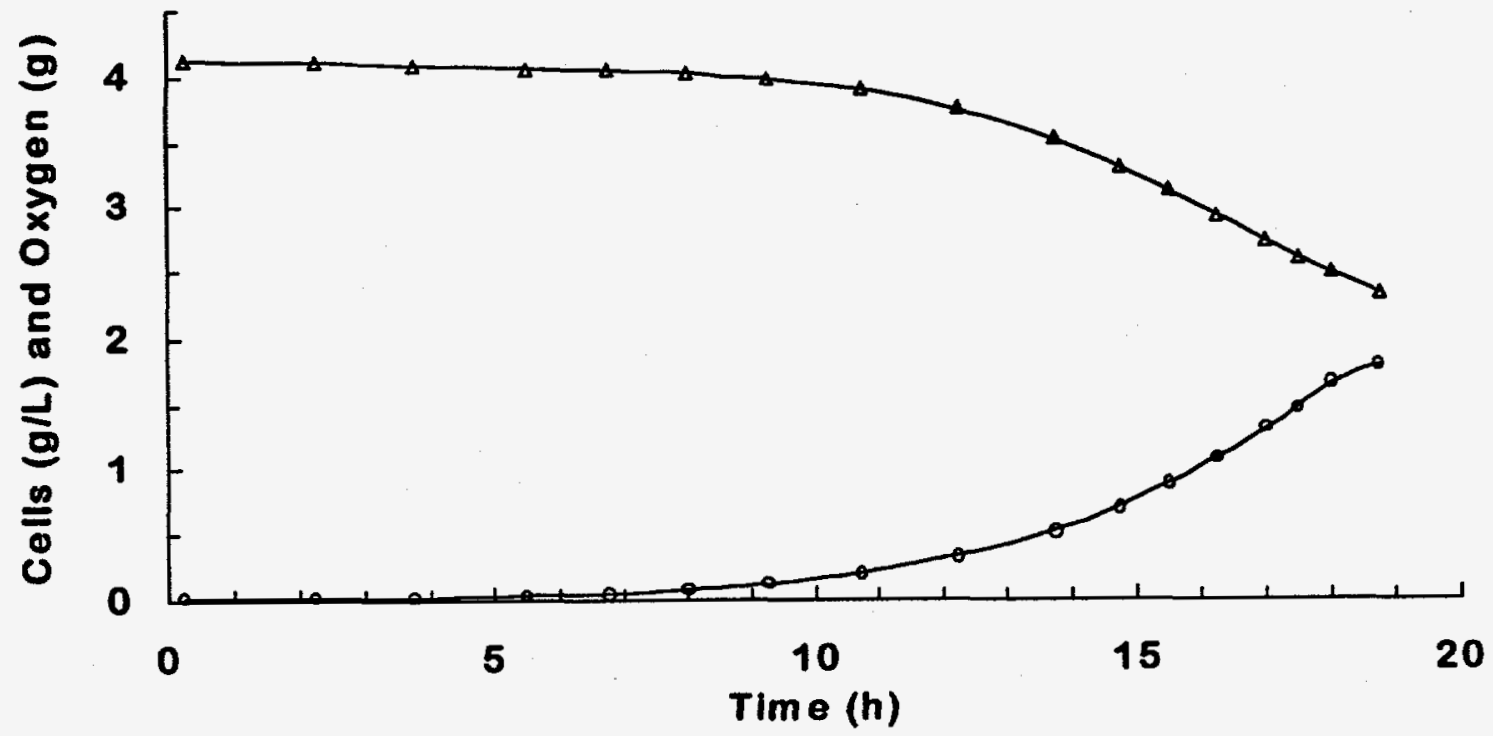




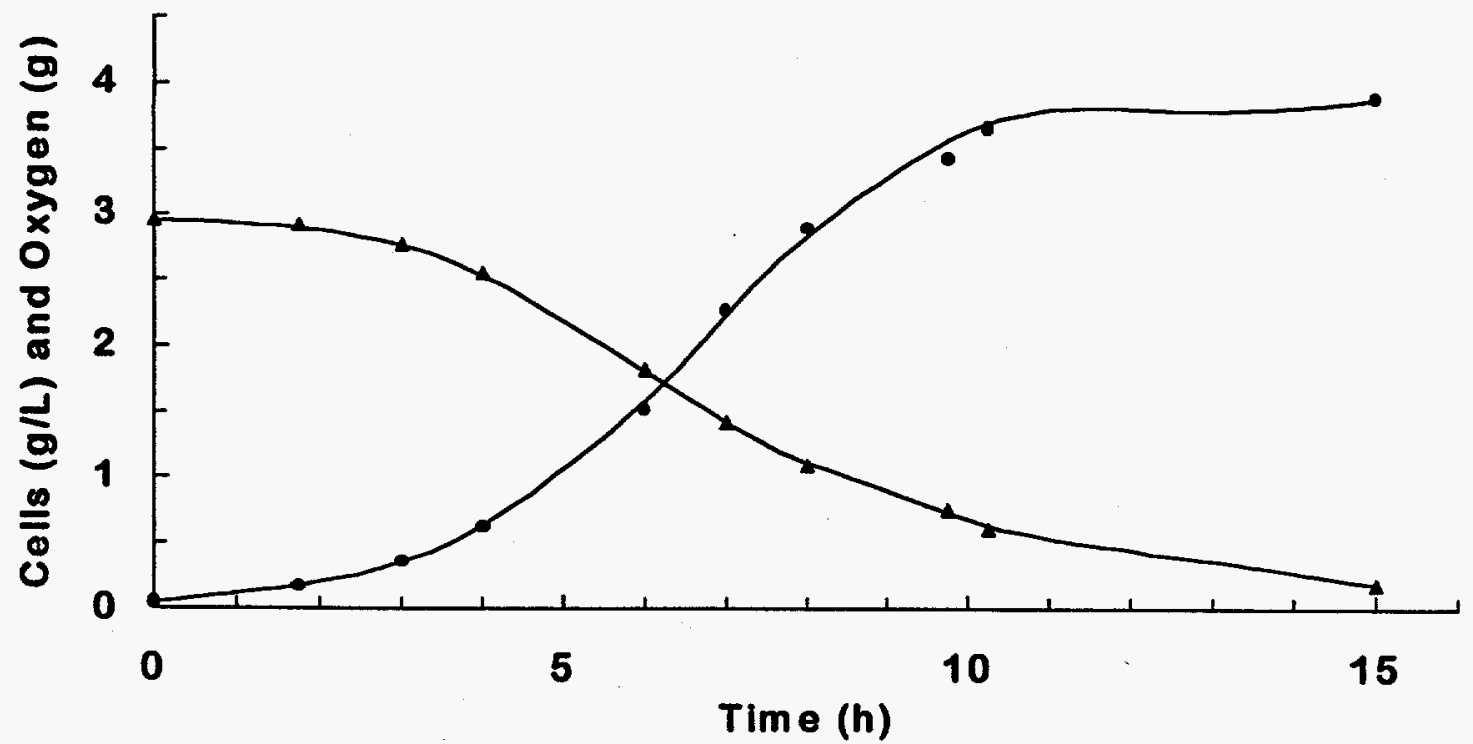




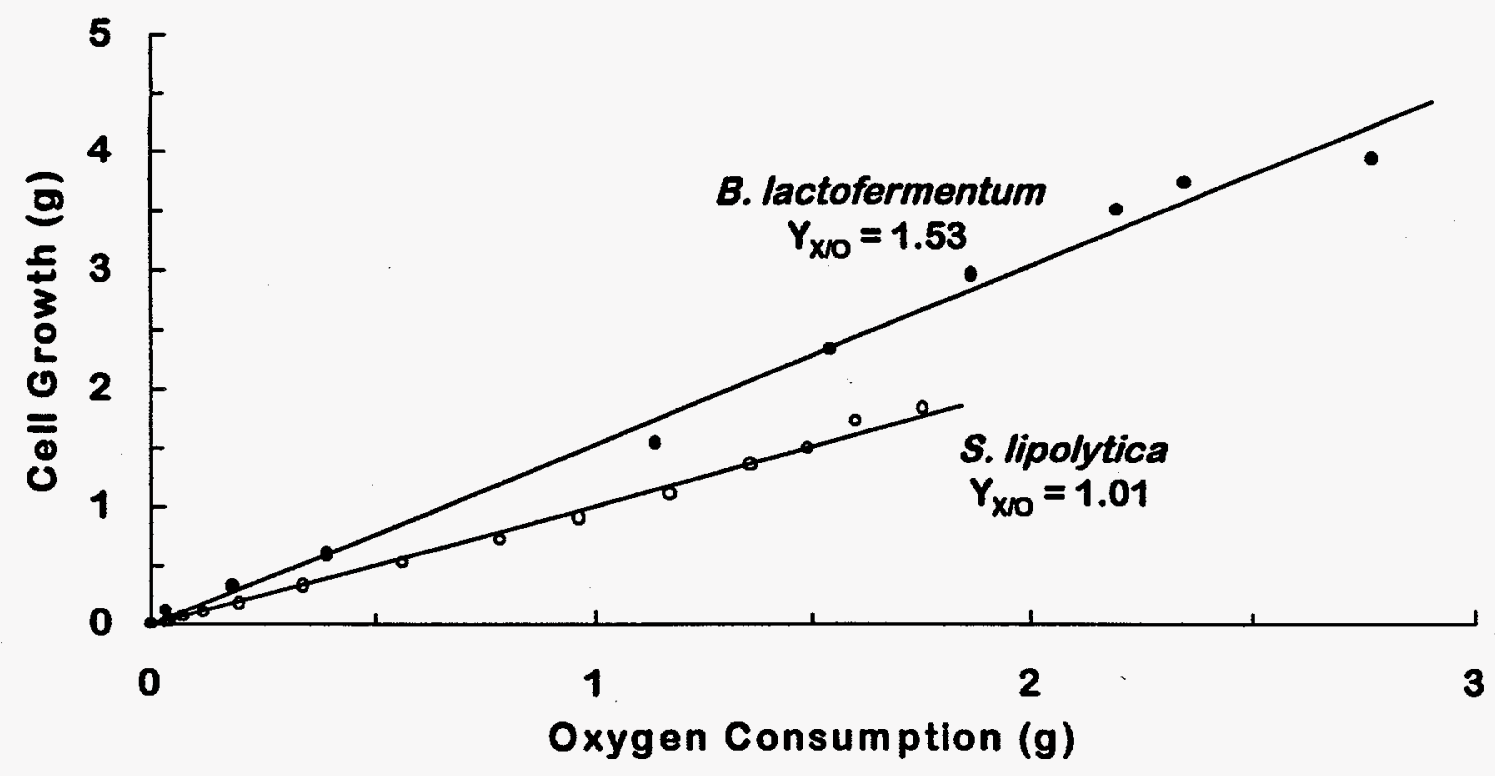




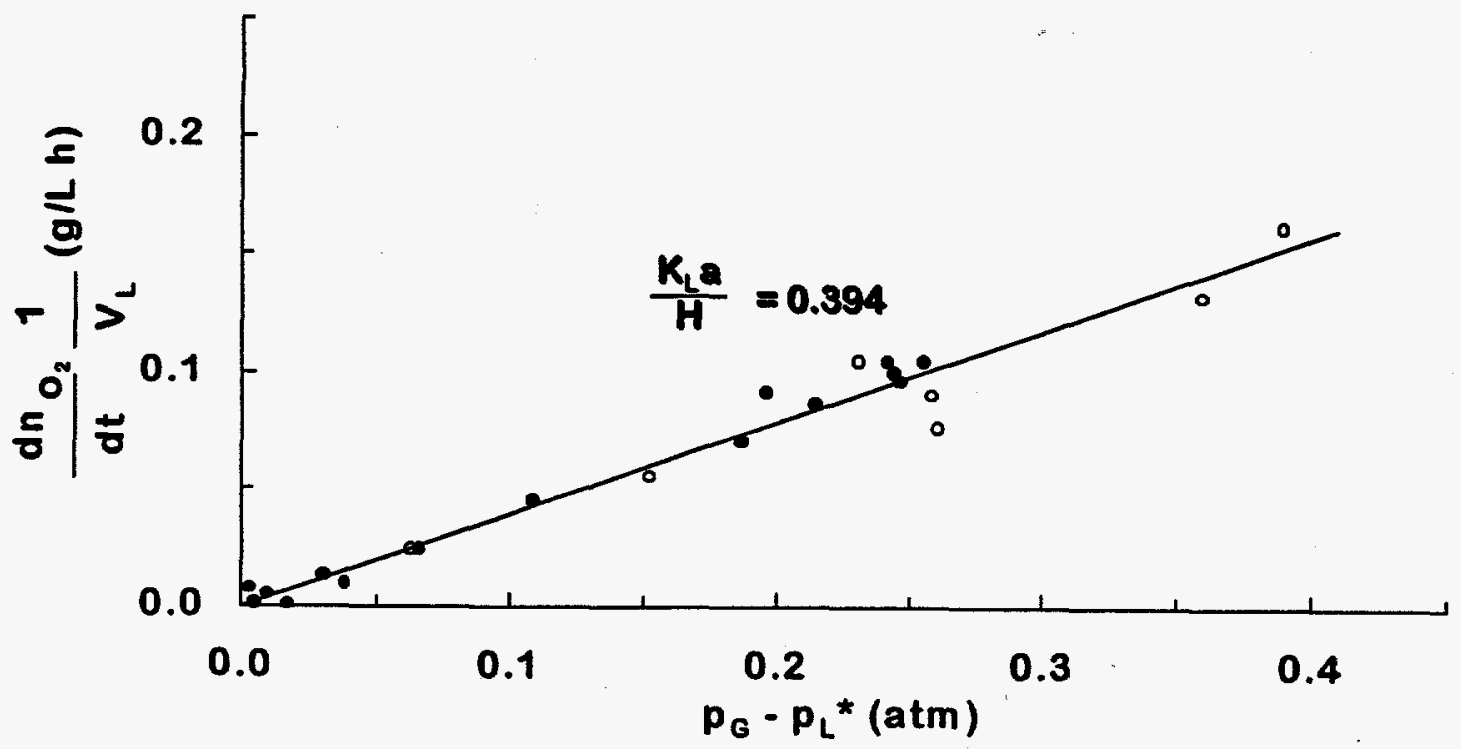

